\title{
Plasticity of the Avian Song Control System in Response to Localized Environmental Cues in an Equatorial Songbird
}

\author{
Ignacio T. Moore, ${ }^{1}$ John C. Wingfield, ${ }^{2}$ and Eliot A. Brenowitz ${ }^{2,3}$ \\ ${ }^{1}$ Department of Biology, Virginia Polytechnic Institute and State University, Blacksburg, Virginia 24061-0406, and Departments of ${ }^{2}$ Biology and \\ ${ }^{3}$ Psychology, University of Washington, Seattle, Washington 98195
}

\begin{abstract}
A striking feature of the vertebrate brain is its plasticity. In high-latitude vertebrates, seasonal plasticity of the brain is driven by ubiquitous photoperiod cues and therefore is highly predictable and synchronous across extensive geographic ranges. A pronounced example of seasonal brain plasticity occurs in the nuclei that regulate song behavior in songbirds. These nuclei are larger in breeding than in nonbreeding birds. In the tropics, photoperiod varies little annually, and other environmental cues important for breeding can show considerable local geographic variability. We investigated whether localized patterns of seasonal breeding in tropical birds are associated with brain plasticity. We studied two populations of rufous-collared sparrows (Zonotrichia capensis) that breed, only $25 \mathrm{~km}$ apart, on the equator but out of phase with each other. We measured gonadal activity and the size of song nuclei (high vocal center, robust nucleus of the arcopallium, and area $\mathrm{X}$ ) during each population's breeding and nonbreeding periods. Breeding males had larger song nuclei and greater gonadal activity than did nonbreeding birds. This plasticity was associated with local environmental cues, such that the two populations exhibit asynchronous changes in brain structure. These results demonstrate the sensitivity of the brain and its ability to use a variety of environmental cues to coordinate seasonal plasticity and reproduction.
\end{abstract}

Key words: behavior; song; telencephalon; reproduction; testosterone; gonad

\section{Introduction}

Seasonal plasticity of the brain has been demonstrated in every class of vertebrate, but only in species that breed at high latitudes (Nottebohm, 1981; Tramontin and Brenowitz, 2000). This plasticity mediates the expression of seasonally appropriate behaviors (Tramontin and Brenowitz, 2000) and is highly synchronous both within and among populations as a result of the ubiquitous nature of photoperiod, the primary initial predictive environmental cue for breeding in these high-latitude species (Wingfield and Kenagy, 1991). The majority of vertebrate species, however, live at tropical latitudes (up to $80 \%$ of passerine bird species) (Stutchbury and Morton, 2001) and therefore experience little seasonal change in day length. Breeding in these tropical animals is often seasonal and associated with annual patterns of temperature, rainfall, and/or food availability (Wikelski et al., 2000, 2003; Hau, 2001; Stutchbury and Morton, 2001). Such environmental cues can show pronounced variability in occurrence over even short geographic distances in the tropics (Bendix and Rafiqpoor, 2001). No studies have described seasonal plasticity in

Received June 15, 2004; revised Sept. 28, 2004; accepted Sept. 29, 2004.

I.T.M. was supported by a National Science Foundation (NSF) postdoctoral fellowship (DBI-9904144) and a Society for Neuroscience postdoctoral fellowship (T32 MH20069). This research was supported by National Institute of Mental Health Grant MH53032 (to E.A.B.) and by NSF Grant IBN-9905679 (to J.C.W.). This project was authorized by the Ministerio del Ambiente of Ecuador. We thank the Fundación Terra and Patricio and Carmen Muñoz for assistance in the field, Lynn Erckmann, George Bentley, and Karen Lent for assistance in the laboratory, and Lisa Belden for statistical advice. M. Ryan and three anonymous referees offered helpful comments on this manuscript.

Correspondence should be addressed to Ignacio T. Moore, Department of Biology, Virginia Polytechnic Institute and State University, 2119 Derring Hall, Blacksburg, VA 24061. E-mail: itmoore@vt.edu.

DOI:10.1523/JNEUROSCI.3475-04.2004

Copyright $\odot 2004$ Society for Neuroscience $\quad$ 0270-6474/04/2410182-04\$15.00/0 the brain of any tropical vertebrate or in any vertebrate in association with environmental cues other than photoperiod, nor have any studies examined the effects of local variations in such factors on neural substrates for breeding-related behaviors.

Song behavior plays a crucial role in avian reproduction, both for territory defense and mate attraction (Catchpole and Slater, 1995). Song learning and production are regulated by a network of interconnected brain nuclei collectively known as the song control system (Zeigler and Marler, 2004). These nuclei form two primary pathways, the descending motor circuit and the anterior forebrain circuit. Song is produced seasonally, with birds singing primarily or only during breeding. Associated with seasonal changes in song behavior is pronounced seasonal plasticity of the song control nuclei in the brain, including the nidopallial nucleus high vocal center (HVC), the robust nucleus of the arcopallium (RA), and area X (X), part of the medial striatum and considered homologous to a portion of the basal ganglia (Tramontin and Brenowitz, 2000). These three nuclei are up to $200 \%$ larger in volume and occupy a larger proportion of the telencephalon during the breeding season than during the nonbreeding season (Tramontin and Brenowitz, 2000). It is thought that seasonal reproduction and changes in the brains of high-latitude species are driven by changes in photoperiod (Tramontin et al., 1998; Tramontin and Brenowitz, 2000; Dawson et al., 2001). These photoperiodic cues in turn induce changes in circulating testosterone through activation of the hypothalamic-pituitarygonadal axis (Wingfield and Kenagy, 1991). Testosterone is the primary physiological cue regulating seasonal changes in the song control system (Smith et al., 1997). Seasonal changes in the neural song control system have been demonstrated in all northern- 
latitude species that have been examined (Tramontin and Brenowitz, 2000) but have not been investigated in tropical-latitude species in which seasonal changes in photoperiod are less pronounced, and changes in other environmental cues show a high degree of local geographic variation. The purpose of this study is to determine whether seasonal changes in brain structure can be mediated by local environmental cues. More specifically, we investigated whether birds living on the equator, and thus experiencing little change in photoperiod, exhibit plasticity in structure of the neural song control system.

\section{Materials and Methods}

Field studies. We investigated two populations of the rufous-collared sparrow, Zonotrichia capensis, that are year-round residents in the high Andes of Ecuador and experience annual changes in day length of only $\sim 3$ min (on-line day length calculator; United States Naval Observatory, Astronomical Applications Department). The two sites (Papallacta: $0^{\circ} 21.7^{\prime}$ South, $78^{\circ} 9.0^{\prime}$ West, $3300 \mathrm{~m}$ elevation; Pintag: $0^{\circ} 22.6^{\prime}$ South, $78^{\circ} 22.5^{\prime}$ West, $2900 \mathrm{~m}$ elevation) are $\sim 25 \mathrm{~km}$ apart, but the populations are geographically separated by high-elevation mountains $(\sim 4000 \mathrm{~m})$. Despite their proximity, these sites experience dramatically different climate patterns, particularly rainfall, as a result of being on opposite slopes of the Andes [for climate data, see Bendix and Rafiqpoor (2001)]. For example, July is the wettest month of the year in Papallacta but the driest month in Pintag. At both sites, the wetter months average $\sim 20 \mathrm{~cm}$ of rain, whereas the dry ones average $5-10 \mathrm{~cm}$ of rain. This difference in climate patterns is associated with opposed reproductive patterns in the rufous-collared sparrow populations between the sites. The Papallacta population breeds at the end of the rainier season, whereas the Pintag population breeds during the rainier season (I. T. Moore, F. Bonier, and J. C. Wingfield, unpublished observations). In an ongoing study of $>600$ individually color-banded birds, we have documented seasonal reproduction that is out of phase between the Papallacta and Pintag populations, despite their residing at the same latitude and thus experiencing the same photoperiod (Moore, Bonier, and Wingfield, unpublished observations). Individuals in the Papallacta population breed from August to December and undergo feather molt in February, whereas in the Pintag population, breeding occurs from November to May with feather molt occurring in June. Males of this species only sing during the breeding season and not during molt or the nonbreeding period. During the breeding period, males have elevated plasma levels of testosterone that are as high as those observed in closely related northern species (Moore et al., 2002, 2004a,b).

Birds were captured, over a single year, from the two populations during each one's respective breeding and nonbreeding periods (Papallacta: breeding, $n=6$, September 16-24, 2002; nonbreeding, $n=7$, April 25-30, 2002; Pintag: breeding, $n=7$, February 20-24, 2003; nonbreeding, $n=6$, August $28-31,2002$ ). In each of the sampling periods, adult individuals in the populations were confirmed to be in the appropriate reproductive condition through behavioral observation (singing, nest building, incubating eggs, and feeding young). Birds were captured passively, without the use of song playback or decoys to attract the birds, soon after dawn using mist nets. Rapidly after capture ( $<10 \mathrm{~min}$ ), a 250 $\mu \mathrm{l}$ blood sample was obtained and stored on ice until return from the field. The blood samples were then centrifuged, and the plasma was separated and frozen. The same day as capture, the birds were perfused with $0.9 \%$ heparinized saline followed by $10 \%$ neutral buffered formalin. The brains were removed and postfixed, under refrigeration, until return to the University of Washington (Seattle, WA). The brains were cryoprotected in 30\% sucrose until they sank, frozen on dry ice, and stored in a $-80^{\circ}$ freezer. Testis size was measured after perfusion, and volume was calculated using a formula for ellipsoid cylinders $\left(4 / 3 \pi a^{2} b\right.$ where " $a$ " is half the testis width and " $b$ " is half the length).

Hormone and brain analyses. Blood samples were analyzed in duplicate by radioimmunoassay for testosterone (Moore et al., 2002). Briefly, steroids were extracted from plasma using dichloromethane and subsequently purified and separated by chromatography using diatomaceous earth columns. Plasma testosterone concentrations were corrected for individual extraction efficiency. The limit of detection for the assay was $\sim 0.08 \mathrm{ng} / \mathrm{ml}$ and depended on the volume of the plasma sample (mean, $106 \mu \mathrm{l}$; range, $28-150 \mu \mathrm{l}$ ). The samples were run in three assays with intra-assay and interassay variations of 7.2 and $16.8 \%$, respectively.

Each brain was sectioned in the coronal plane at $40 \mu \mathrm{m}$ on a cryostat, and every third section was Nissl stained. Brain sectioning and Nissl staining were always done on pairs of brains, one from each population. Song nuclei volumes were measured and calculated as described previously (Smith et al., 1995; Brenowitz et al., 1998; Tramontin et al., 1998). Briefly, a magnified $(46 \times)$ image of each stained section was projected onto paper, and the profiles of the telencephalic song nuclei HVC, RA, and $\mathrm{X}$ were traced. Traces were scanned into a computer, and the area was calculated using NIH Image software (version 1.57; Wayne Rasband, National Institutes of Health, Bethesda, MD). The volume of each nucleus was calculated using the formula for a cone frustum over each measured profile area. As a control for individual or group differences in overall brain size, we divided the volume of each song nucleus by the volume of the entire telencephalon (Tramontin et al., 2000). The volume of the entire telencephalon, on one side of the brain, was estimated by projecting a magnified $(14 \times)$ image of every sixth mounted section through the entire telencephalon. Previous studies in closely related species have not reported size differences between the left and right sides of the telencephalon (Tramontin et al., 2000). The volume for the one side was calculated, as for the song control nuclei, and that volume was doubled. We divided each individual's song nuclei volumes by the volume of that individual's telencephalon and multiplied by 100 . This provided the proportion of the telencephalon that is occupied by the song control nuclei HVC, RA, and X.

Statistical analysis. For statistical analysis, we performed a multivariate ANOVA (MANOVA) with population (Papallacta, Pintag), reproductive state (breeding, nonbreeding), and population by reproductive state as explanatory variables and testis volume, plasma testosterone level, and the proportion of the telencephalon occupied by HVC, RA, and X as response variables. Subsequently, individual ANOVAs were conducted on the five response variables using the same explanatory variables. Significance levels for the univariate tests were adjusted based on sequential Bonferroni adjustments by the Dunn-Sidák method (Sokal and Rohlf, 1995).

\section{Results}

All measured traits differed significantly between breeding and nonbreeding sparrows within each population (Fig. 1, see Table 1 for complete statistics). The MANOVA showed an overall significant effect of reproductive state $\left(F_{(5,18)}=22.50 ; p<0.001\right)$ but not population or the interaction between population and reproductive state. This same pattern, a significant effect of reproductive state but not population or the interaction between reproductive state and population, occurred in each of the individual ANOVAs for the reproductive traits (testis volume, $F_{(1,22)}=$ 62.40, $p<0.001$; testosterone, $\left.F_{(1,22)}=15.81, p<0.001\right)$ and the proportion of the telencephalon occupied by each song control nucleus $\left(\mathrm{HVC}, F_{(1,22)}=12.98, p=0.002 ; \mathrm{X}, F_{(1,22)}=9.25, p=\right.$ 0.006 ; RA, $\left.F_{(1,22)}=6.51, p=0.018\right)$. At the time of year when birds in the Papallacta population were breeding (August to September), birds in Pintag were in a nonbreeding state. Correspondingly, the song control nuclei were fully grown in the breeding Papallacta population when they were regressed in the nonbreeding Pintag population (Fig. 1). Singing behavior also changed seasonally in both populations. During the dawn chorus, in each population, an average of 144 songs were counted from all birds during a 5 min sampling period during the breeding season, but no songs were heard during the nonbreeding season.

\section{Discussion}

Proper timing of breeding is crucial for reproductive success. In high-latitude species, change in photoperiod is the initial predic- 

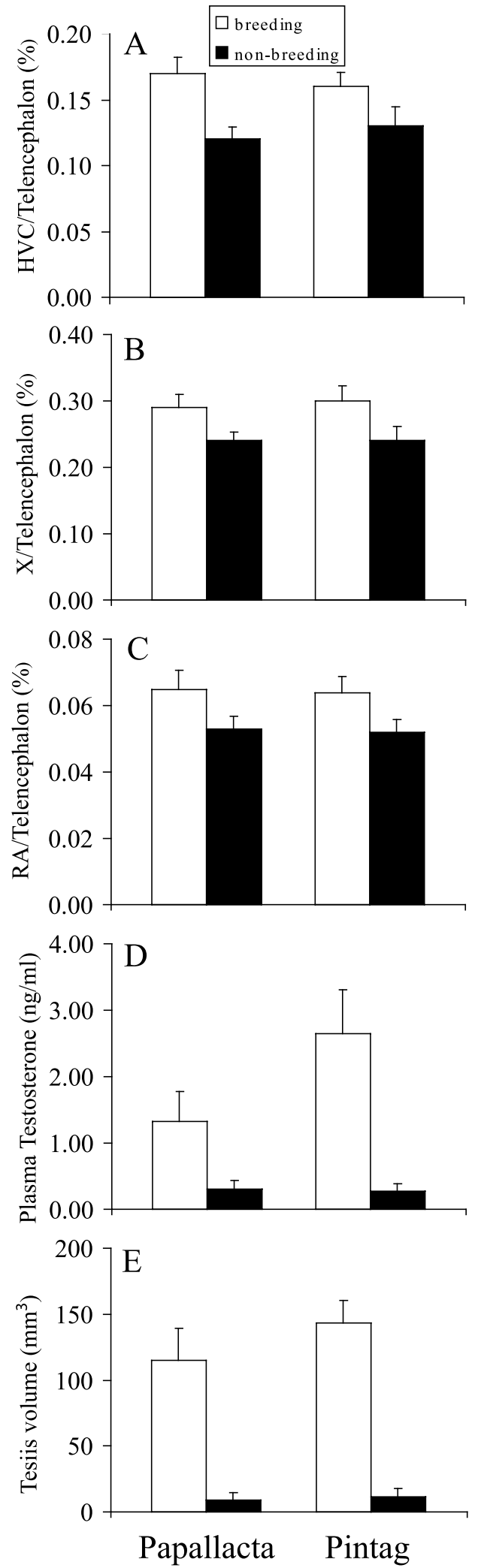

Figure 1. Seasonal changes in the volumes of the song control nuclei $(A, H V C ; B, X ; C, R A)$ and gonadal activity ( $D$, testosterone; $E$, testis size) between breeding and nonbreeding individuals in the two equatorial populations of rufous-collared sparrows, Z. capensis. There were statistically significant effects of reproductive state (breeding vs nonbreeding), but not population or the interaction term between these two factors (see Table 1), on all of the response variables. Breeding birds from Papallacta were collected at the same time of year as nonbreeding birds from Pintag. These results demonstrate the extreme degree of flexibility in the plasticity of the neural song control system in Z. capensis.
Table 1. Comparisons of song system nuclei and reproductive condition between rufous-collared sparrows, Zonotrichia capensis, from the two populations sampled during their respective breeding and nonbreeding periods

\begin{tabular}{lrcc}
\hline & \multicolumn{1}{c}{$F$} & df & \multicolumn{1}{c}{$p$} \\
\hline MANOVA & & & \\
$\quad$ Intercept & 306.799 & 5,18 & $<0.001^{*}$ \\
$\quad$ Population & 0.731 & 5,18 & 0.609 \\
$\quad$ Reproductive state & 22.502 & 5,18 & $<0.001^{*}$ \\
$\quad$ Population X reproductive state & 1.463 & 5,18 & 0.251 \\
ANOVAs & & & \\
Testis volume & & & \\
$\quad$ Population & 0.985 & 1,22 & 0.332 \\
$\quad$ Reproductive state & 62.401 & 1,22 & $<0.001^{*}$ \\
$\quad$ Population X reproductive state & 0.737 & 1,22 & 0.400 \\
Testosterone & & & \\
$\quad$ Population & 2.312 & 1,22 & 0.143 \\
$\quad$ Reproductive state & 15.811 & 1,22 & $<0.001^{*}$ \\
$\quad$ Population X reproductive state & 2.560 & 1,22 & 0.124 \\
HVC & & & \\
$\quad$ Population & 0.026 & 1,22 & 0.873 \\
$\quad$ Reproductive state & 12.981 & 1,22 & $0.002^{*}$ \\
$\quad$ Population X reproductive state & 0.945 & 1,22 & 0.342 \\
X & & & \\
$\quad$ Population & 0.034 & 1,22 & 0.856 \\
$\quad$ Reproductive state & 9.252 & 1,22 & $0.006^{*}$ \\
$\quad$ Population X reproductive state & 0.109 & 1,22 & 0.745 \\
RA & & & \\
Population & 0.007 & 1,22 & 0.932 \\
$\quad$ Reproductive state & 6.506 & 1,22 & $0.018^{*}$ \\
$\quad$ Population X reproductive state & 0.002 & 1,22 & 0.968 \\
\hline
\end{tabular}

Results are for the overall MANOVA as well as the individual ANOVAs. Explanatory variables are population (Papallacta, Pintag) and reproductive state (breeding, nonbreeding) and the interaction between the two. Asterisks denote a statistically significant result. Significance level for univariate tests on reproductive state were 0.0102 (testis volume), 0.0127 (testosterone), 0.0170 (HVC), $0.0253(\mathrm{X})$, and 0.05 (RA), based on sequential Bonferron adjustments by the Dunn-Sidák method. HVC, X, and RA volumes are analyzed as a percentage of the total volume of the telencephalon.

tive cue used to time seasonal processes such as reproduction because of its ultimate predictability (Wingfield and Kenagy, 1991; Dawson et al., 2001). Variations in the local environment can then be used to modify the precise timing of reproduction (Wingfield and Kenagy, 1991). However, seasonal reproduction can also occur in tropical environments and can be associated with seasonal changes in other environmental cues such as rainfall (Stutchbury and Morton, 2001). In every high-latitude species that has been studied, seasonal reproduction is associated with seasonal changes in the brain (Tramontin and Brenowitz, 2000), especially the song control system in songbirds. To our knowledge, this is the first study to describe seasonal changes in the brain of a tropical vertebrate. Because the majority of species (up to $80 \%$ of passerine birds) are tropical, they have evolved very different life-history patterns from high-latitude species (Stutchbury and Morton, 2001). Our study demonstrates that although the environmental cues timing reproduction are different between high-latitude and tropical species, the seasonal changes in the brain that govern seasonal behaviors appear to be similar.

Our observation of seasonal brain plasticity in these tropical birds demonstrates that the vertebrate brain is extremely flexible and sensitive to diverse environmental cues that can time seasonal reproductive physiology and behavior. Two lines of evidence demonstrate that photoperiod is not the critical seasonal cue for these populations of rufous-collared sparrows. First, both populations live year-round on the equator, where seasonal changes in day length are minimal. Second, the two populations have reproductive cycles that are out of phase with each other, despite residing at the same latitude and thus experiencing the 
same photoperiod. It is also worth noting that the two populations sing different song dialects, and females exhibit reproductive cycles that are synchronous with those of the males described here (Moore, Bonier, and Wingfield, unpublished observations). Although it is unclear exactly which environmental cues are used to synchronize reproductive timing within each population, rainfall, temperature, and associated food availability are likely candidates and have been demonstrated to be important cues for other tropical bird species (Dittami and Gwinner, 1985; Wikelski et al., 2000, 2003; Stutchbury and Morton, 2001; Leitner et al., 2003). It is likely that the birds in the current study used all possible environmental cues, because properly timing reproduction is crucial. It is therefore noteworthy that the song system is sensitive to such local climatic variations. These results suggest that plasticity of the song control system is not limited to species that breed at high latitudes but rather may be common to all species that breed seasonally, regardless of latitude. This observation is important, because $80 \%$ of passerine species are tropical, and most tropical birds exhibit seasonal breeding (Stutchbury and Morton, 2001).

The results of the current study suggest that global climate change could have effects on animals through a mechanism that has not been explored previously. It is well established that global warming is having adverse effects on living organisms (Thomas et al., 2004). Some of these effects occur through changes in the timing of seasonal processes (Parmesan and Yohe, 2003), such as reproduction (Brown et al., 1999; Winkler et al., 2002). Global climate change does not affect photoperiod, the ubiquitous initial predictive cue used by high-latitude species, but does affect temperature and rainfall patterns. Our study demonstrates that tropical vertebrates may be sensitive to these locally variable environmental cues and that these cues can affect the structure of the brain and associated seasonal physiological processes and behavior. These results suggest that global climate change could affect the timing of seasonal physiological processes through changes in the structure and function of the brain.

A fundamental feature of nervous systems is that they provide plasticity of structure and function that allows animals to adapt to their environment. In the case of male songbirds, the brain controls the release of testosterone into the circulation, which has feedback effects on the morphology and physiology of the brain and ultimately on behavior. Thus, brain plasticity serves as a crucial link between the environment and seasonally appropriate behaviors. Our results suggest an extreme degree of flexibility in the ability of the brain to make use of a variety of environmental cues that may vary seasonally. Although the pattern of seasonal change within the song system takes the same form in highlatitude and tropical songbird species, the environmental cues that induce these changes in the brain clearly differ with latitude.

\section{References}

Bendix J, Rafiqpoor MD (2001) Studies on the thermal conditions of soils at the upper tree line in the paramo of Papallacta (eastern cordillera of Ecuador). Erdkunde 55:257-276.

Brenowitz EA, Baptista LF, Lent K, Wingfield JC (1998) Seasonal plasticity of the song control system in wild Nuttall's white-crowned sparrows. J Neurobiol 34:69-82.
Brown JL, Li SH, Bhagabati N (1999) Long-term trend toward earlier breeding in an American bird: a response to global warming? Proc Natl Acad Sci USA 96:5565-5569.

Catchpole CK, Slater PJB (1995) Bird song: biological themes and variations. Cambridge, UK: Cambridge UP.

Dawson A, King VM, Bentley GE, Ball GF (2001) Photoperiodic control of seasonality in birds. J Biol Rhythms 16:365-380.

Dittami JP, Gwinner E (1985) Annual cycles in the African stonechat Saxicola torquata axillaris and their relationship to environmental factors. J Zool (Lond) 207:357-370.

Hau M (2001) Timing of breeding in variable environments: tropical birds as model systems. Horm Behav 40:281-290.

Leitner S, Van't Hof TJ, Gahr M (2003) Flexible reproduction in wild canaries is independent of photoperiod. Gen Comp Endocrinol 130:102-108.

Moore IT, Perfito N, Wada H, Sperry TS, Wingfield JC (2002) Latitudinal variation in plasma testosterone levels in birds of the genus Zonotrichia. Gen Comp Endocrinol 129:13-19.

Moore IT, Walker BG, Wingfield JC (2004a) The effects of combined aromatase inhibitor and anti-androgen on male territorial aggression in a tropical population of rufous-collared sparrows, Zonotrichia capensis. Gen Comp Endocrinol 135:223-229.

Moore IT, Wada H, Perfito N, Busch DS, Wingfield JC (2004b) Territoriality and testosterone in an equatorial population of rufous-collared sparrows, Zonotrichia capensis. Anim Behav 67:411-420.

Nottebohm F (1981) A brain for all seasons: cyclical anatomical changes in song-control nuclei of the canary brain. Science 214:1368-1370.

Parmesan C, Yohe G (2003) A globally coherent fingerprint of climate change impacts across natural systems. Nature 421:37-42.

Smith GT, Brenowitz EA, Wingfield JC, Baptista LF (1995) Seasonal changes in song nuclei and song behavior in gambel's white-crowned sparrows. J Neurobiol 28:114-125.

Smith GT, Brenowitz EA, Beecher MD, Wingfield JC (1997) Seasonal changes in testosterone, neural attributes of song control nuclei, and song structure in wild songbirds. J Neurosci 17:6001-6010.

Sokal RR, Rohlf FJ (1995) Single-classification analysis of variance. In: Biometry: the principles and practice of statistics in biological research, Chap 9, Ed 3, pp 207-271. New York: Freeman.

Stutchbury BJM, Morton ES (2001) Behavioral ecology of tropical birds. San Diego: Academic.

Thomas CD, Cameron A, Green RE, Bakkenes M, Beaumont LJ, Collingham YC, Erasmus BFN, Ferreira de Siqueira M, Grainger A, Hannah L, Hughes L, Huntley B, van Jaarsved AS, Midgley GF, Miles L, Ortega-Huerta MA, Peterson AT, Phillips OL, Williams SE (2004) Extinction risk from climate change. Nature 427:145-148.

Tramontin AD, Brenowitz EA (2000) Seasonal plasticity in the adult brain. Trends Neurosci 23:251-258.

Tramontin AD, Wingfield JC, Brenowitz EA (1998) Contributions of social cues and photoperiod to seasonal plasticity in the adult avian song control system. J Neurosci 19:476-483.

Tramontin AD, Hartman VN, Brenowitz EA (2000) Breeding conditions induce rapid and sequential growth in adult avian song control circuits: a model of seasonal plasticity in the brain. J Neurosci 20:854-861.

Wikelski M, Hau M, Wingfield JC (2000) Seasonality of reproduction in a neotropical rain forest bird. Ecology 81:2458-2472.

Wikelski M, Hau M, Robinson WD, Wingfield JC (2003) Reproductive seasonality of seven neotropical passerine species. Condor 105:683-695.

Wingfield JC, Kenagy GJ (1991) Natural regulation of reproductive cycles. In: vertebrate endocrinology: fundamentals and biomedical implications (Pawg PKT, Schreibruan MP, eds), pp 181-241. San Diego: Academic.

Winkler DW, Dunn PO, McCulloch CE (2002) Predicting the effects of climate change on avian life-history traits. Proc Natl Acad Sci USA 99:13595-13599.

Zeigler HP, Marler P (2004) Behavioral neurobiology of birdsong, Vol 1016. New York: Annals of the New York Academy of Science. 